\title{
An Ethical Framework for Communicating Public Health Crises: A Case Analysis of the COVID-19 Pandemic
}

\author{
Qingjiang (Q. J.) Yao \\ Department of Communication \& Media, Lamar University \\ 4400 MLK PkWy, Beaumont, TX 77710, USA
}

\begin{abstract}
These Identifying the traditional principle of medical ethics of autonomy as a major factor that hinders epidemiological investigation and the understanding of a novel virus, this study adopts an ethical framework, consisting of the axes of ethical devotions (local, national, continental, and global) and ethical reasoning approaches (deontological and teleological), to analyze the approaches of communicating global public health crises like the COVID pandemic. The argument is made to endorse a global devotion with teleological reasoning in a large-scale public health crisis that needs global collaboration to cope with.
\end{abstract}

Keywords - Autonomy, COVID-19, Ethical devotions, Ethical framework, Ethical orientation

SUGGESTED CITATION: Yao, Q. J. (2021). An ethical framework for communicating public health crises: A case analysis of the COVID-19 pandemic. Proceedings of the International Crisis and Risk Communication Conference, Volume 4 (pp. 8-11). Orlando Fl: Nicholson School of Communication and Media. https://doi.org/10.30658/icrcc.2021.02

\section{INTRODUCTION: THE COVID-19 PANDEMIC AS A GLOBAL CRISIS}

COVID-19 has taken the whole world by a big surprise with its global scale, the number of people it has affected and killed, and its duration as a pandemic. By the end of February 2021, it has been active for longer than one year, already sickened more than 114 million people, and taken more than 2.5 million lives worldwide. While the current priority is still coping with the pandemic, reducing its global influence, and bringing the world back to normalcy, some reflections can be conducted to better our continuing handling of the pandemic and our responses next time in the same situation with a global infectious or contagious public health crises. One of such reflections is how to ethically communicate and frame public health crises of such nature to the public.

Judging from the numbers of people infected and died, developed societies with advanced health systems have not been all very effective in handling the COVID pandemic. While many factors can be attributed to this low effectiveness, a factor that stands out in this research is the most conspicuous principle of traditional medical ethics: autonomy, which hinders epidemiological investigation and tracing and therefrom the understanding of the novel coronavirus. Epidemiological investigation is a critical measure to contain the spreading of the coronavirus and the escalation of the pandemic in the current age of glocalization that has been facilitated by advances of informational technology and the volume of human mobilization [1].

This study adopts an ethical framework, consisting of the axes of ethical devotions (local, national, continental, and global) and ethical reasoning approaches (deontological and teleological) [2], to analyze the stances of communicating public health crises like the COVID pandemic. The argument is made to endorse global teleology, in comparison with the strict and to some degree intrusive security-check measures that have been installed globally since the $9 / 11$ tragedy in 2001. This argument for the ethical stance of global teleology in public health crises is in urgent need at a time when global collaboration is critical to coping with many public health and environmental crises, mostly now at global scales, but the awareness of such collaboration has not been solidified [3].

\section{PRINCIPLES OF BIOMEDICAL AND PUBLIC HEALTH ETHICS}

An influential guideline of biomedical ethics has been Tom Beauchamp and James Childress's Principles of Biomedical Ethics (PBE), published in their book with the same title [4], which contains four moral principles: respect for autonomy 
(respecting the patient's self-direction of his or her life and choices), nonmaleficence (avoiding the causation of harm to the patient), beneficence (providing benefits and balancing benefits against risks to the patient), and justice (distributing benefits, risks, and costs fairly). The PBE framework and its variations have dominated ethical research and practices on medical issues, branding "respect for autonomy" a prior principle in the medical, health care, and public health professions [5].

The PBE framework, particularly the principle of respect for autonomy, also implies additional principles such as protecting patients' privacy and confidentiality [6][7]. Those are effective ethical principles for regular medical and health research or practices, but in the case of dealing with an epidemic or pandemic, when strategies of early identification, reporting, isolation, and management are key to control the virus transmission [10], prioritizing or indoctrinating those principles could impede the crisis management during an epidemic or pandemic and let it spread into an uncontrollable scale, as we have seen in the current Globe. Moreover, protests globe wide in the name of preserving autonomy and defending the right not to comply with public-health measures have clearly worsened the situation. A different ethical framework for public health communication and practice in the epidemic or pandemic situation should be adopted.

\section{A FRAMEWORK OF ETHICAL ANALYSIS}

An ethical framework that was developed to analyze media coverage of disasters [2] and differentiate journalism and activism [8] is adopted to guide the communication and decision-making of public health crises and particularly pandemics. The framework for ethical analysis, in a form of a coordinate system, consists of the axes of ethical devotions and ethical reasoning approaches, both points of ethical analysis in the literature [9].

Ethical devotion refers to the entity to whom the ethical decision-maker is devoted, which can range from just one person (usually the decision-maker him- or herself, thus generating egoism) to groups/societies of different sizes (in the case of public health, visibly at the levels of localism, nationalism, continentism, and globalism). A society-oriented ethical devotion can be in the positive form of collectivism (focusing on achieving the overall wellbeing in society), or individualism (focusing on protecting the society members' fundamental wellbeing). Individualism defends the same rights or wellbeing for every member of the society, and so it is different from egoism, which cares only about the wellbeing of the ethical decision-maker. In a pandemic, globalism is naturally the appropriate devotion for the world to cope with the crisis of public health collaboratively and effectively [3]

Ethical reasoning approaches noticeably include deontology (value- or duty-based) and teleology (results-based). Values or duties that serve as the foundation for deontological reasoning are normally consensuses that emerged from long-time ethical practices within a society or culture, and they serve as heuristics for decision-makers to conduct daily ethical analyses. When values or duties are not universal across societies or cultures, which can happen on a global scale, teleological reasoning needs to be the fundamental approach of ethical analysis [2] [8] (Figure 1).

Figure 1: An Ethical Framework to analyze communications and decision-making of the COVID-19 Pandemic

\begin{tabular}{|l|l|}
\hline Globalism & Ethical \\
stance to \\
communi \\
cate a
\end{tabular}




\section{METHODS}

The study uses the method of concept and theoretical analysis, which reaches the conclusions by arguments derived from existing ethical concepts, theories, and evidence.

\section{RESULTS}

The ethical framework consists of two axes of analysis: ethical devotion and ethical reasoning approach. Given the scope of a pandemic, no other ethical devotions except the global devotion can handle it effectively. Nationalism, which dominates the current world due to the reinforcement of the political and economic status quo, may restrain the global collaboration that is urgently demanded to contain a pandemic or solve other issues of global scope [3]. In particular, the positive form of globalism should be adopted to achieve the maximum of the wellbeing of the world. The negative form, which although should reach the same decision as does the positive form if the ethical reasoning or calculation is appropriate, can be used with a misleading emphasis. For instance, the insistence on autonomy and privacy has dismantled the measures of early identification and isolation and destroyed the efforts of controlling the transmission at a manageable level in many advanced societies.

On the surface, insistence on autonomy and privacy still devotes itself to globalism or at least nationalism, as it may argue that the defense of such principles is for everyone in the society. But when it is clear that the spreading of the coronavirus threatens the lives and health of many others, such insistence turns itself to be devoted to only those who want to overemphasize autonomy and privacy during a pandemic, rendering it no longer a negative form of globalism or nationalism but in fact a form of egoism. While those insisters may or may not be entitled to have the autonomy to ignore the virus' threat to their lives (suicide is unethical in any culture), their insistence on moving freely or not wearing masks while possibly carrying coronavirus infringes others' rights to protect their lives or health.

Along the ethical reasoning approach axis, both deontology and teleology can be used to communicate about the pandemic. Although autonomy and privacy are the values that deontologists can use as the basis of ethical reasoning, preserving lives should be a value of a higher rank. When the rank of values is in dispute and controversies are generated around the measures to control the spreading of a pandemic or other crises, teleological reasoning should be used the produce practically good results. The security measures installed globe-wide at the airports after the 911 tragedy that took about three thousand lives are a good example: despite their inconvenience and intrusion, they have been embraced as a daily norm from 2001 to the foreseeable future.

So in a sum, the ethical stance of global teleology should be adopted to communicate and make decisions about the COVID pandemic. No area or country can handle such a public health threat alone, and no insistence on other values less important than saving lives should be in the way to effectively contain and control the spreading of this pandemic.

\section{DISCUSSION}

Many models of ethical analysis have helped people to make decisions in difficult situations [9], including the PEB framework of Tom Beauchamp and James Childress that has been taken as classical in the medical and health professions [4]. The PEB framework, with its emphasis on autonomy and privacy, has worked adequately in situations when patients' situations have little impact on others in the society. During an epidemic or pandemic, one person's decision on how to treat the virus that he or she potentially carries can influence many others. The PEB framework can then be misleading or harmful to collective efforts of containing the spreading of the virus, as we have seen in the past year.

Analysis through the ethical coordinate system adopted in this study suggests that a global teleological ethical stance should be adopted to cope with a pandemic like COVID-19 or other similar public health crises with a global scope. Not every ethical decision-making demands a global teleological approach; in many situations, devoting to local or national societies or reasoning along the deontological approach based on existing values or duties may be more economic and easier to conduct. Indeed, the nationalism devotion has been much more dominating than the globalism devotion, as the former has support from the existing political and economic infrastructures. As technology and human mobilization integrate the world more and many issues turn to be global crises, such as pandemic diseases, climate change, international peace, global poverty, and the unknown beyond the current human frontier, the ethical stance of global teleology will be more on-demand to establish global collaboration and solve those common challenges.

\section{CONCLUSION}

Communications and decision-making about a public health crisis like the pandemic COVID-19 can be analyzed with their ethical devotions and ethical reasoning approaches. Ethical devotions can be to oneself, producing egoism, or to societies of different sizes (localism, nationalism, continentism, and globalism), generating collectivism in the positive form or individualism in the negative form. Coping with a pandemic like COVID-19 demands a globalism devotion in the positive form, as the negative form (in the form of overemphasizing autonomy and privacy) may be misleading and create hurdles for adopting epidemiological investigation and other measures of pandemic containment and control. 
Ethical reasoning can be conducted in a deontological approach or a teleological approach. Values or duties serving as the basis for deontological reasoning are consensuses that emerged from long-time teleological calculations and are heuristics for immediate reasoning on complex issues. So teleological reasoning is more fundamental and more effective when values or duties are not universal across cultures or societies. To summon global collaboration to deal with the threat of pandemic COVID-19 or other crises with a global scope, a global teleological stance is needed to communicate and make decisions.

\section{Author Biography}

Dr. Q. J. Yao, associate professor of Communication at Lamar University, Beaumont, Texas, studies communication effects and ethics in the digital era and particularly on science and health issues.

\section{REFERENCES}

[1] Boudreau, M-C., Loch, K. Robey, D., \& Straud, D. (1998). Going global: Using information technology to advance the competitiveness of the virtual transnational organization. Academy of Management Perspectives, 12(4), 120-128. https://doi.org/10.5465/ame.1998.1334008

[2] Yao, Q. J., \& C. S. Eigemann. (2013). Building a coordinate system: An ethical framework for analyzing media coverage of disasters. American Communication Journal, 15(2), 1-16. Available at: https://pdfs.semanticscholar.org/46fd/2797c5416fcd1bd76d9692fcfcc6e70f6bf7.pdf

[3] Robertson, R. (1995). Glocalization: Time-space and homogeneity and heterogeneity. In M. Featherstone, S. Lash, \& R. Robertson (eds). Global modernities (pp. 25-44). Thousand Oaks, CA: Sage Publications

[4] Beauchamp, T. L., \& Childress, J. F. (2021). Principles of biomedical ethics, $17^{\text {th }}$ ed. New York: Oxford University Press.

[5] Jennings, B., \& Arras, J. (2008). Ethical guidance for public health emergency preparedness and response: Highlighting ethics and values in a vital public health service. A white paper prepared for the Ethics Subcommittee, Advisory Committee to the Director, Center for Disease Control and Prevention. Available at: https://stacks.cdc.gov/view/cdc/44130

[6] Coughlin, S. S. (2008). How many principles for public health ethics? Open Public Health Journal, 1, 8-16. https://doi.org/10.2174/1874944500801010008

[7] Christen, M., Ineichen, C., \& Tanner, C. (2014). How "moral" are the principles of biomedical ethics?-A cross-domain evaluation of the common morality hypothesis. BMC Medical Ethics, 15, 47. https://doi.org/10.1186/1472-6939-15-47

[8] Yao, Q. (2020). Good or bad for whom and what: A revised ethical framework to differentiate journalism and activism. Presented to Broadcast Education Association's \#BEAVirtualVegas Conference, April 2020. Available at: https:/www.slideshare.net/QingjiangQJYao/good-or-bad-for-whom-and-what-a-revised-ethical-frameworkto-differentiate-journalism-and-activism

[9] Patterson, P., \& Wilkins, L. (2004). Media ethics: Issues \& cases (5th ed.). Boston, MA: McGraw Hill.

[10] Zhong, N., \& Zeng, G. (2006). What we have learnt from SARS epidemics in China. BMJ (Clinical research ed.), 333(7564), 389-391. https://doi.org/10.1136/bmj.333.7564.389 